\title{
TINJAUAN KEPATUHAN DOKTER DALAM PENGISIAN DOKUMEN REKAM MEDIS RAWAT INAP DI RUMAH SAKIT UMUM IMELDA PEKERJA INDONESIA (RSU IPI) MEDAN TAHUN 2018
}

\author{
Marta Simanjuntak \\ Dosen APIKES Imelda, Jalan Bilal Nomor 52 Medan \\ E-mail: $\underline{\text { mmartasimanjuntak@gmail.com }}$
}

\begin{abstract}
ABSTRAK
Kelengkapan rekam medis merupakan hal yang sangat penting karena berpengaruh terhadap proses pelayanan yang dilakukan oleh petugas medis dan mempengaruhi kualitas dari pelayanan suatu rumah sakit tersebut. Rekam medis harus dibuat dengan lengkap setelah pasien menerima pelayanan. Penelitian ini bertujuan untuk mengetahui kepatuhan dokter dalam pengisian Catatan Perkembangan Pasien Terintegrasi (CPPT) pada berkas rekam medis rawat inap di Rumah Sakit Umum Imelda Pekerja Indonesia (RSU IPI) Medan Tahun 2018. Jenis penelitian yang dipakai dalam penelitian ini adalah penelitian deskriptif yang bertujuan untuk menggambarkan situasi yang ada ditempat penelitian dengan menggunakan metode observasi. Populasi pada penelitian ini adalah berkas rekam medis pada formulir Catatan Perkembangan Pasien Terintegrasi (CPPT) di periode Maret-Mei 2018 dengan jumlah 1518 berkas rekam medis. Sampel dalam penelitian ini adalah berkas rekam medis pada formulir Catatan Perkembangan Pasien Terintegrasi (CPPT) di Rumah Sakit Umum Imelda Pekerja Indonesia (RSU IPI) Medan berjumlah 94 berkas. Berdasarkan hasil dan pembahasan penelitian yang berjudul "Tinjauan Kepatuhan Dokter Dalam Pengisian Dokumen Rekam Medis Rawat Inap di Rumah Sakit Umum Imelda Pekerja Indonesia (RSU IPI) Medan Tahun 2018 "khususnya pada berkas Catatan Perkembangan Pasien Terintegrasi (CPPT) dapat disimpulkan bahwa kepatuhan Dokter dalam mengisi Catatan Perkembangan Pasien Terintegrasi (CPPT) masih rendah.
\end{abstract}

Kata Kunci : Kepatuhan Dokter, Kelengkapan Berkas Rekam Medis Khususnya Catatan Perkembangan Pasien Terintegrasi (CPPT).

\section{PENDAHULUAN}

Kelengkapan rekam medis merupakan hal yang sangat penting karena berpengaruh terhadap proses pelayanan yang dilakukan oleh petugas medis dan mempengaruhi kualitas dari pelayanan suatu rumah sakit tersebut. Rekam medis harus dibuat dengan lengkap setelah pasien menerima pelayanan. Hal ini dijelaskan dalam PERMENKES No. 269/MENKES/PER/III/2008 Tentang Reka $\mathrm{m}$ Medis dalam pasal 5 ayat 1 menyatakan bahwa "Setiap dokter atau dokter gigi dalam menjalankan praktik kedokteran wajib membuat rekam medis", dan ayat 2 "Rekam medis sebagaimana dimaksud pada ayat (1) harus dibuat segera dan dilengkapi setelah pasien menerima pelayanan kesehata n".

Kelengkapan dalam pengisian berkas rekam medis oleh dokter akan dapat memudahkan tenaga kesehatan lain dalam memberikan tindakan atau pengobatan pada pasien, dan dapat dijadikan sebagai sumber data pada bagian rekam medis dalam pengelolaan data dan laporan yang akan dijadikan informasi yang berguna bagi pihak manajemen rumah sakit dalam menentukan evaluasi dan pengembangan pelayanan kesehatan (Hatta, 2014).

Masalah yang sering timbul dalam pengisian rekam medis adalah dalam proses pengisiannya tidak lengkap, penulisan dokter yang kurang spesifik mengenai 
diagnosa. Keadaan ini akan megakibatkan dampak bagi intern dan ekstern rumah sakit, karena hasil pengolahan data menjadi dasar pembuatan laporan intern rumah sakit dan laporan ekstern rumah sakit. Laporan ini berkaitan dengan penyusunan berbagai perencanaan rumah sakit, pengambilan keputusan oleh pimpinan khususnya evaluasi pelayanan yang telah diberikan yang diharapkan hasil evaluasinya akan menjadi lebih baik (Giyana, 2012). Melihat pentingnya kelengkapan data pada rekam medis bagi dokter, tentunya berkaitan dengan perilaku dokter sendiri dalam melengkapi data pasien pada rekam medis.

Salah satu dari form berkas rekam medis yang penting adalah Catatan Perkembangan Pasien Terintegrasi (CPPT). CPPT adalah catatn perkembangan pasien sejak pertama kali mendapat pelayanan kesehatan yang meliputi catatan perkembang an kesehatan masa lalu sampai saat ini yang mencakup bio psikososio spritual. CPPT ditulis oleh : dokter yang terlibat dalam menangani pasien. CPPT ditulis dengan menggunakan metode Subjective, Objective, Analisis, Planning (SOAP).

Dari survey yang telah dilakukan oleh penulis, pada bulan April 2018 di Rumah Sakit Umum Imelda Pekerja Indonesia (RSU IPI) Medan di instalasi rekam medis pada bagian analisa rekam medis, penulis menemukan angka kelengkapan asesmen awal medis dalam 24 jam pada pasien rawat inap di Rumah Sakit Umum Imelda Pekerja Indonesia (RSU IPI) Medan, pada bulan Maret tahun 2017 berkas rekam medis yang lengkap sebanyak $96 \%$ dan berkas rekam medis yang tidak lengkap sebanyak $4 \%$. Kendala dokter dalam pengisian dokumen rekam medis adalah waktu karena dokter ada pekerjaan di rumah sakit lain dan dokter memiliki banyak pasien, oleh sebab itu masalah terjadi di RSU. Imelda Pekerja Indonsia (RSU. IPI) Medan ketidaklengkapa $\mathrm{n}$ ini dapat berakibat pada mutu isi dokumen rekam medis dan tingkat IRM (Incomplet Medical Record) menjadi lebih tinggi.

\section{METODE}

\section{Jenis Penelitian}

Jenis penelitian yang dipakai dalam penelitian ini adalah penelitian deskriptif yang bertujuan untuk menggambarkan situasi yang ada ditempat penelitian dengan menggunakan metode observasi.

\section{Waktu dan Tempat Penelitian}

Penelitian dilaksanakan pada bulan Juli 2018. Penelitian ini dilakukan di Rumah Sakit Umum Imelda Pekerja Indonesia (RSU IPI) Medan yang berlokasi di Jl. Bilal No. 24 Pulo Brayan Darat I Medan Timur.

\section{Populasi}

Populasi pada penelitian ini adalah berkas rekam medis pada formulir Catatan Perkembangan Pasien Terintegrasi (CPPT) di periode Maret-Mei 2018 dengan jumlah 1518 berkas rekam medis.

\section{Sampel}

Sampel dalam penelitian ini adalah berkas rekam medis pada formulir Catatan Perkembangan Pasien Terintegrasi (CPPT) di Rumah Sakit Umum Imelda Pekerja Indonesia (RSU IPI) Medan berjumlah 94 berkas. Rumus Slovin mencari sampel :

$$
\begin{gathered}
n=\frac{\mathrm{N}}{1+\mathrm{N}\left(\mathrm{d}^{2}\right)} \\
n=\frac{1518}{1+1518\left(0,1^{2}\right)} \\
n=\frac{1518}{1+1518(0,01)} \\
n=\frac{1518}{1+15,18} \\
n=\frac{1518}{16.18} \\
n=93,8 \text { berkas }
\end{gathered}
$$

Dibulatkan menjadi 94 berkas.

Keterangan :

$n=$ Jumlah Sampel

$\mathrm{N}=$ Jumlah Populasi

$\mathrm{d}=$ Tingkat Kepercayaan (0.1)

\section{Teknik Pengumpulan Data}

Data primer yaitu data yang diperoleh langsung dari subjek penelitian melalui daftar check list pada subjek sebagai sumber informasi yang dicari. Data sekunder yaitu 
data yang diperoleh peneliti dari subjek penelitiannya. Data sekunder pada penelitian ini adalah data yang diperoleh dari bagian rekam medis di Rumah Sakit Umum Imelda Pekerja Indonesia (RSU IPI) Medan.

\section{Variabel Penelitian}

Variabel adalah karakteristik yang diamati dan mempunyai variasi nilai dan merupakan operasionalisasi dari suatu konsep agar dapat diteliti secara empiris atau ditentukan tingkatannya. Variabel peneliti yaitu: SDM (Dokter Umum, Dokter Syaraf, Dokter Anak dan Dokter Penyakit Dalam) dan Data rekam medis CPPT (Nama Dokter, Anamnese, Diagnosa Medis, Tanda Tangan Dokter, Therapy Pasien, Jam Tindakan, Tanggal Rawatan).

\section{Definisi Operasional}

Defenisi operasional merupakan penjelasan semua variabel dan istilah yang akan digunakan dalam penelitian secara operasional sehingga akhirnya mempermudah pembaca dalam mengartikan makna penelitian.

1. Sumber daya manusia adalah tenaga kesehatan yang berprofesi sebagai tenaga medis dan non medis lainnya yang bertanggung jawab atas pelayanan yang diberikan kepada pasien, Contoh SDM: dokter, perawat, tenaga medis dan non medis lainnya.

2. Dokter adalah orang yang memiliki kewenangan dan izin sebagaimanamestinya untuk melakukan pelayanan kesehatan, khususnya memeriksa dan mengobati penyakit dan dilakukan menurut hukum dalam pelayanan kesehatan. Dokter yang dimaksud adalah Dokter Umum, Dokter Syaraf, Dokter Anak dan Dokter Penyakit Dalam.

3. Data Rekam medis adalah Data medik pasien selama pasien mendapatkan pelayanan dirumah sakit, salah satu data rekam medis berupa lembar formulir CPPT (catatan perkembangan pasien terintegrasi) yang harus di isi oleh dokter.

4. Catatan Perkembangan Pasien Terintegrasi (CPPT) adalah proses asuhan pasien yang dilakukan oleh petugas kesehatan dari berbagai unit kerja/pelayanan yang terkoordinasi satu dengan lainnya agar menghasilkan asuhan yang efektif dan efisien.

\section{Teknik Analisis}

1. Analisis data yang digunakan dalam penelitian ini adalah secara deskriptif, yaitu dengan cara mendeskriptifkan data yang telah dikumpulkan untuk meninjau kepatuhan dokter dalam pengisian dokumen rekam medis rawat inap di Rumah Sakit Umum Imelda Pekerja Indonesia (RSU IPI) Medan.

2. Menganalisis kelengkapan berkas rekam medis rawat inap yang diisi oleh dokter meliputi :
a. Nama dokter
b. Anamnese
c. Diagnosa medis
d. Tanda tangan dokter
e. Therapy pasien
f. Jam tindakan
g. Tanggal rawatan

\section{HASIL}

Berdasarkan hasil pengumpulan data oleh peneliti yang berjudul "Tinjauan Kepatuhan Dokter Dalam Pengisian Dokumen Rekam Medis Rawat Inap di Rumah Sakit Umum Imelda Pekerja Indonesia (RSUP) Medan Tahun 2018 khususnya pada formulir Catatan Perkemban gan Pasien Terintegrasi (CPPT)" maka diperoleh data sebagai berikut :

Tabel 1. Hasil Tinjauan Kelengkapan Catatan Perkembangan Pasien Terintegrasi (CPPT) Berdasarkan Nama Dokter, Anamnese, Diagnosa Medis, Tanda Tangan Dokter, Therapy Pasien, Jam Tindakan, Tanggal Rawatan

\begin{tabular}{lcccc}
\hline Catatan Perkembangan & \multicolumn{2}{c}{ Lengkap } & \multicolumn{2}{c}{ Tidak Lengkap } \\
\cline { 2 - 5 } Pasien Terintegrasi & Jumlah & Persen (\%) & Jumlah & Persen (\%) \\
\hline Nama Dokter & 50 & $53,2 \%$ & 44 & $46,8 \%$ \\
\hline Anamnese & 56 & $59,6 \%$ & 38 & $40,4 \%$ \\
\hline
\end{tabular}




\begin{tabular}{lcccc}
\hline Diagnosa Medis & 61 & $64,9 \%$ & 33 & $35,1 \%$ \\
\hline Tanda Tangan Dokter & 35 & $37,2 \%$ & 59 & $62,8 \%$ \\
\hline Therapy Pasien & 62 & $66 \%$ & 32 & $34 \%$ \\
\hline Jam Tindakan & 48 & $51,1 \%$ & 46 & $48,9 \%$ \\
\hline Tanggal Rawatan & 50 & $53,2 \%$ & 44 & $46,8 \%$ \\
\hline
\end{tabular}

Berdasarkan tabel berkas Catatan

Perkembangan Pasien Terintegrasi (CPPT) nama dokter yang lengkap sebanyak 50 berkas $(53,2 \%)$ dan yang tidak lengkap sebanyak 44 berkas $(46,8 \%)$, anamnese yang lengkap sebanyak 56 berkas $(59,6 \%)$ dan yang tidak lengkap sebanyak 38 berkas $(40,4 \%)$, diagnosa medis yang lengkap sebanyak 61 berkas $(64,9 \%)$ dan yang tidak lengkap sebanyak 33 berkas $(35,1 \%)$, tanda tangan dokter yang lengkap sebanyak
35 berkas $(37,2 \%)$ dan yang tidak lengkap sebanyak 59 berkas $(62,8 \%)$, therapy pasien yang lengkap sebanyak 62 berkas $(66 \%)$ dan yang tidak lengkap 32 berkas (34 \%), jam tindakan yang lengkap sebanyak 48 berkas $(51,1 \%)$ dan yang tidak lengkap 46 berkas $(48,9 \%)$, tanggal rawatan yang lengkap sebanyak 50 berkas $(53,2 \%)$ dan yang tidak lengkap sebanyak $44(46,8 \%)$.

Tabel 2. Tabel Tinjauan Kepatuhan Dokter dalam Pengisian Catatan Perkembangan Pasien Terintegrasi Berkas Rekam Medis Rawat Inap di Rumah Sakit Umum Imelda Pekerja Indonesia (RSU IPI) Medan Tahun 2018

\begin{tabular}{|c|c|c|c|c|}
\hline \multirow[t]{2}{*}{ Dokter } & \multicolumn{2}{|c|}{ Lengkap } & \multicolumn{2}{|c|}{ Tidak Lengkap } \\
\hline & Jumlah & Persen (\%) & Jumlah & Persen (\%) \\
\hline Dokter Umum & 23 & $24,4 \%$ & 20 & $21,27 \%$ \\
\hline Dokter Syaraf & 6 & $6,94 \%$ & 4 & $4,25 \%$ \\
\hline Dokter Anak & 9 & $9,57 \%$ & 6 & $6,38 \%$ \\
\hline Dokter Penyakit Dalam & 10 & $10,63 \%$ & 16 & $17,02 \%$ \\
\hline
\end{tabular}

Dokter dalam Pengisian Catatan Perkemban gan Pasien Terintegrasi terjadi pada dokter umum yang terisi lengkap sebanyak 23 berkas $(24,4 \%)$ dan yang tidak lengkap 20 berkas $(21,27 \%)$, dokter syaraf yang terisi lengkap 6 berkas $(6,94 \%)$ dan tidak lengkap 4 berkas $(4,25 \%)$, dokter anak yang terisi lengkap 9 berkas $(9,57 \%)$ dan yang tidak lengkap 6 berkas $(6,38 \%)$, dokter penyakit dalam yang terisi lengkap 10 berkas $(10,63$ $\%)$ dan yang tidak lengkap $16(17,02 \%)$.

\section{PEMBAHASAN}

Berdasarkan hasil penelitian di Rumah Sakit Umum Imelda Pekerja Indonesia (RSU IPI) Medan dengan menggunakan daftar check list tentang kepatuhan Dokter dalam mengisi Catatan Perkembangan Pasien Terintegrasi (CPPT) pada berkas rekam medis rawat inap dari 94 berkas Catatan Perkembangan Pasien Terintegrasi (CPPT) menunjukkan bahwa penulisan nama dokter yang lengkap sebanyak 50 berkas $(53,2 \%)$ dan yang tidak lengkap sebanyak 44 berkas 56 berkas $(59,6 \%)$ dan yang tidak lengkap sebanyak 38 berkas $(40,4 \%)$, diagnosa medis yang lengkap sebanyak 61 berkas $(64,9 \%)$ dan yang tidak lengkap sebanyak 33 berkas $(35,1 \%)$, tanda tangan dokter yang lengkap sebanyak 35 berkas $(37,2 \%)$ dan yang tidak lengkap sebanyak 59 berkas $(62,8 \%)$, therapy pasien yang lengkap sebanyak 62 berkas $(66 \%)$ dan yang tidak lengkap 32 berkas (34\%), jam tindakan yang lengkap sebanyak 48 berkas $(51,1 \%)$ dan yang tidak lengkap 46 berkas (48,9\%), tanggal rawatan yang lengkap sebanyak 50 berkas $(53,2 \%)$ dan yang tidak lengkap sebanyak 44 berkas $(46,8 \%)$.

Berdasarkan hasil penelitian di Rumah Sakit Umum Imelda Pekerja Indonesia (RSU IP) Medan tentang kepatuhan dokter dalam pengisian catatan perkembangan pasien terintegrasi yaitu dokter umum yang lengkap sebanyak 23 berkas $(24,4 \%)$ dan yang tidak lengkap 20 berkas $(21,27 \%)$, dokter syaraf yang lengkap 6 berkas $(6,94 \%)$ dan tidak lengkap 4 berkas $(4,25 \%)$, dokter anak yang lengkap 9 berkas $(9,57 \%)$ dan yang tidak 
lengkap 6 berkas $(6,38 \%)$, dokter penyakit dalam yang lengkap 10 berkas $(10,63 \%)$ dan yang tidak lengkap 16 berkas $(17,02$ $\%)$.

Kepatuhan adalah tingkat perilaku petugas yang tertuju terhadap instruksi atau petunjuk yang diberikan dalam bentuk terapi apapun yang ditentukan, baik diet, latihan, pengobatan atau janji pertemuan dengan dokter (Stanley, 2007). Yang mempengaruhi kepatuhan dokter terhadap pengisian Catatan Perkembangan Pasien Terintegrasi (CPPT) di Rumah Sakit Umum Imelda Pekerja Indonesia (RSU IPI) Medan yaitu :

a. Pengaruh insentif terhadap kepatuhan dokter. Semakin besar insentif petugas di Rumah Sakit Umum Imelda Pekerja Indonesia (RSU IPI) Medan maka petugas semakin patuh dalam pengisian Catatan Perkembangan Pasien Terintegr asi (CPPT).

b. Pengaruh masa kerja terhadap kepatuhan dokter pengalaman seorang petugas di Rumah Sakit Umum Imelda Pekerja Indonesia (RSU IPI) Medan berpengaru h pada kinerjanya karena semakin lama kerja petugas maka keahliannya akan semakin baik.

\section{KESIMPULAN}

Berdasarkan hasil penelitian yang telah di lakukan oleh penulis yang berjudul "Tinjauan Kepatuhan Dokter Dalam Pengisian Dokumen Rekam Medis Rawat Inap di RSU Imelda Pekerja Indonesia (RSU IPI) Medan Tahun 2018 " maka di peroleh kesimpulan sebagai berikut: Seperti yang terdapat dalam tabel hasil tinjauan kelengka pan pengisian pada berkas catatan perkemba ngan pasien terintegrasi (CPPT), mayoritas 1 engkap adalah pencatatan therapy $(66 \%)$, minoritas lengkap adalah pengisian tanda tangan dokter $(37,2 \%)$. Ketidak lengkapan pengisian berkas CCPT mayoritas tidak lengkap adalah pencatatan therapy $(62,8 \%)$, minoritas tidak lengkap adalah tanda tangan dokter (34\%). Seperti yang terdapat dalam tabel hasil keatuhan dokter dalam pengisian berkas catatan perkembangan pasien terinteg rasi (CPPT), mayoritas lengkap adalah dokter umum $(24,45)$, minoritas lengkap adalah dokter syaraf (6,94\%). Ketidak patuhan pengisian berkas CCPT mayoritas tidak lengkap adalah dokter syaraf $(21,27$ \%minoritas tidak lengkap adalah dokter umum $(4,25 \%)$.

\section{SARAN}

Berdasarkan hasil penelitian yang dilakukan penulis tentang Kepatuhan Dokter dalam Pengisian Catatan Perkembangan Pasien Terintegrasi Berkas Rekam Medis Rawat Inap di Rumah Sakit Umum Imelda Pekerja Indonesia (RSU IPI) Medan, maka peneliti dapat memberikan saran sebagai berikut :

1. Petugas Pengisian CPPT

Petugas pengisian berkas CPPT di RSU. Imelda Pekerja Indonesia (RSU. IPI) diharapkan dapat meningkatkan kepatuh an pengisian berkas CPPT, sehingga dapat meningkatkan mutu pelayana dan dapat mengurangi tingkat IRM (Incompl et Medical Record), serta informasi pada berkas rekam medis lebih lengkap dan akurat.

2. Direktur Rumah Sakit

Sebagai direktur rumah sakit diharapkan untuk tidak menerima tenaga medis, dengan dua tempat kerja atau lebih, dengan demikian tenaga medis memiliki waktuk banyak dalam melakukan pengisian berkas CPPT dapat terlaksana dengan baik, jelas dan lengkap, serta menghasilkan berkas CPPT bermutu, dan memiliki informasi yang lengkap dan akurat. Sebagai direktur rumah sakit diharapkan untuk memberikan sosialisas i pengisian berkas rekam medis bagi tenaga medis yang baru diterima.

\section{DAFTAR PUSTAKA}

Anderson, Elisabeth T. (2009). Buku Ajar Keperawatan Komunitas Teori Dan Praktek. Jakarta : EGC.

Astuti, Endang Kusuma. (2009). Transaksi Teraupetik Dalam Upaya Pelayanan Medis Di Rumah Sakit. Bandung: Citra Aditya Bakti. 
Budi, Citra Sapitri. (2011). Manajemen Unit Kerja Rekam Medis .Yogyakarta: Quantum Sinergis Media.

Giyana, F. (2012). Analisis Sistem Pengelola an Rekam Medis Rawat Inap Rumah Sakit Umum Daerah Kota Semarang. J urnal Kesehatan Masyarakat.

Hatta, Gemala R. (2014). Pedoman Manaje men Informasi Kesehatan Di Sarana Pelayanan Kesehatan. Jakarta: UI Press.

Ivancevich. (2007). Peilaku dan manajemen organisasi. Jakarta: Erlangga.

Kementrian Kesehatan RI. PERMENKES RI Nomor 269 tahun 2008 tentang Rekam Medis.

Notoatmodjo, S. (2007). Metodologi Peneliti an Kesehatan. Jakarta: Rineka Cipta.
Notoatmodjo, S. (2010). Metodologi Peneliti an Kesehatan. Jakarta: Rineka Cipta.

Notoatmodjo, S. (2012). Metodologi Peneliti an Kesehatan. Jakarta: Rineka Cipta.

Rustiyanto, Ery. (2009). Etika Profesi: Perekam Medis Informasi Kesehatan.Y ogyakarta: Graha Ilmu.

Saryono. (2013). Metodologi Penelitian Kualitatif dan Kuantitatif dalam Bidang Kesehatan. Yogyakarta: Nuha Medika.

Stanley. (2007). Buku Ajar Keperawatan Gerontik. Jakarta: EGC.

Sukmadinata. (2007). Metode Penelitian Pendidikan. Bandung: Rosdakarya.

Swansburg. (2011). Kemampuan dan Manaj emen Keperawatan Untuk Perawat Klinik. Jakarta: EGC. 